\title{
MANEJO QUÍMICO DA FERRUGEM ASIÁTICA DA SOJA, BASEADO EM DIFERENTES MÉTODOS DE MONITORAMENTO
}

\author{
C.G. Gardiano ${ }^{1}$, M.G. Balan ${ }^{2}$, J. Falkoski Filho ${ }^{1}$, L.C.M. de Camargo ${ }^{1}$, G.M. de Oliveira ${ }^{1}$, \\ W.T. Igarashi ${ }^{1}$, L.T. Sudo ${ }^{1}$, S. Igarashi ${ }^{1}$, O.J.G. Abi Saab ${ }^{1}$, M.G. Canteri ${ }^{1}$ \\ ${ }^{1}$ Universidade Estadual de Londrina, Centro de Ciências Agrárias, Departamento de Agronomia, Laboratório \\ de Fitopatologia, CP 6001, Cep.EP 86051-990, Londrina, PR, Brasil. E-mail: cris_gardiano@hotmail.com
}

\section{RESUMO}

\begin{abstract}
O objetivo do trabalho foi determinar o momento ideal da aplicação dos fungicidas de ação preventiva, (Opera + Assist)* e (PrioriXtra + Nimbus)*, baseado na detecção inicial de primeiros esporos associado às condições ambientais, monitoramento climático e monitoramento convencional (após a detecção dos primeiros sintomas), verificando sua eficiência no controle da ferrugem asiática da soja. O trabalho foi desenvolvido na fazenda Escola da Universidade Estadual de Londrina, onde foram instalados coletores de esporos na área para detecção dos primeiros esporos e também se fez anotação das condições climáticas obtidas em estação metereológica. As aplicações foram feitas a 1, 7, 14 e 21 dias após detecção dos primeiros esporos, seguindo o monitoramento climático e monitoramento convencional. Foram avaliadas a porcentagem da área foliar infectada, desfolha e produtividade de grãos. Observou-se uma menor porcentagem de infecção foliar, quando os produtos foram aplicados logo no início da detecção dos primeiros esporos (1, 7 e 14 dias após detecção) e seguindo o monitoramento climático e, apesar do produto (PrioriXtra +Nimbus)* ter apresentado menores porcentagens de infecção foliar e desfolha quando aplicado nos diferentes momentos, observou-se que na produtividade de grãos não houve diferença entre os produtos testados.
\end{abstract}

PALAVRAS-CHAVE: Phakopsora pachyrhizi, coletor de esporos, momento de aplicação.

\section{ABSTRACT}

CHEMICAL MANAGEMENT OF THE SOYBEAN ASIAN RUST BASED ON DIFFERENT MONITORING METHODS. The objective of this study was to determine the ideal time for the application of the fungicides of preventive action (Opera + Assist)* and (PrioriXtra + Nimbus) ${ }^{*}$, based on the initial detection of early spores associated with environmental conditions, climate monitoring and conventional monitoring (after the detection of the first symptoms), verifying their effectiveness in the control of Asian soybean rust. The study was conducted at the Londrina State University ExperimentalStation, where spore collectors were installed in the area for early detection of spores and the climate conditions were monitored in a climate station. The applications were made at 1, 7, 14 and 21 days after first detection of spores, according to the climate monitoring and conventional monitoring. Evaluations were made of the infected leaf area, defoliation and soybean yield. There was a lower percentage of leaf infection when the products were applied early in the detection of spores (1, 7 and 14 days after detection), and according to the climate monitoring. Moreover, despite that the product (Nimbus + PrioriXtra)* presented lower percentages of infected leaf and defoliation when applied at the different times, it was observed that in the final yield of the crop there was no difference between the products tested.

KEY WORDS: Phakopsora pachyrhizi, spore collector, time of application.

\section{INTRODUÇÃO}

A soja é considerada uma das principais culturas produzidas mundialmente, no entanto, existem vários fatores que limitam a sua produção e a sua produtividade no Brasil. Entre esses podem-se destacar as adversidades climáticas, ocorrência de vários insetos nocivos, plantas

${ }^{2}$ Faculdade Integrado de Campo Mourão, Campo Mourão, PR, Brasil.

*O produto comercial utilizado no trabalho não implica em recomendação pelo autor. 
daninhas e as doenças. Segundo YORINORI (2002), atualmente existem cerca de 50 doenças de soja catalogadas no Brasil e, dentre essas doenças, a ferrugem asiática, causada pelo fungo Phakopsora pachyrhizi Sydow, é a que vem provocando maiores níveis de danos à cultura, devido a sua rápida disseminação e virulência.

O manejo desta doença é feito principalmente pelo emprego do controle químico, através da aplicação de fungicidas, em função da inexistência de cultivares comerciais resistentes. Para auxiliar na definição do momento inicial de aplicação foram criados vários tipos de programas pelas diversas entidades como: programas Syntinelas, Consórcio antiferrugem, S.O.S. Soja, Mini-lab, Radar, Aura e outros.

Contudo, há programas alternativos de controle da ferrugem asiática que prezam a prevenção, baseando-se nas condições climática para definir o momento de aplicação. Esses programas levam em consideração temperatura, umidade e tempo de molhamento foliar, favoráveis ao patógeno. No entanto, segundo ReIs (2004), se considerarmos os fatores determinantes na ocorrência de doenças, ou seja, planta suscetível, patógeno infectivo e ambiente favorável, é possível perceber que esses sistemas de alerta possuem falhas em sua metodologia, pois a tomada de decisão independe da presença do patógeno na área, levando em consideração apenas a presença do hospedeiro e de condições ambientais favoráveis.

Com isso, apesar da redução dos preços da maioria dos fungicidas, o custo do controle tem aumentado devido ao crescente número de aplicações. Sendo assim, o emprego inadequado destes fungicidas tem prejudicado a sua eficácia no controle da ferrugem asiática, variando grandemente em função da condição de aplicação (SILVA, 2003). Um exemplo disso é que a mesma molécula pode apresentar alta eficiência no controle da ferrugem, se for aplicada preventivamente e, baixa eficácia se for aplicada curativamente (DUARTE, 2004). A maior parte dos produtos disponíveis no mercado possui característica de controle preventivo. Tem-se aumentado as reclamações sobre redução da eficácia e período residual dos produtos, com aplicações sequenciais sendo feitas em intervalos de 10 a 12 dias (YORINORI, 2006).

Deste modo, estratégias químicas protetoras utilizadas em caráter regional, amparadas por sistemas armadilha, em plantas ou caça esporos, ainda serão as ferramentas disponíveis para o manejo econômico e eficiente das ferrugens da soja nas próximas safras (BALARDIM, 2006). Com isso, técnicas como a previsão de doenças, que auxiliam os produtores na tomada de decisão para o controle químico de doenças, têm aumentado de importância (REIS, 2004).

O objetivo do trabalho foi determinar o momento ideal da aplicação dos produtos de ação preventiva, (Opera + Assist)* e (PrioriXtra + Nimbus)*, baseado na detecção inicial dos primeiros esporos associado às condições ambientais, monitoramento climático (Sistema Aura - aplicação do produto quando a umidade relativa for maior que $80 \%$ ) e monitoramento convencional (aplicação do produto após a detecção dos primeiros sintomas), verificando sua eficiência no controle da ferrugem asiática da soja.

\section{MATERIAL E MÉTODOS}

O experimento foi conduzido na fazenda Escola da Universidade Estadual de Londrina, no Município de Londrina, PR, com a altitude aproximada de $560 \mathrm{~m}$, sob clima classificado como Cfa, segundo Köpen, e precipitação média anual de $1.600 \mathrm{~mm}$.

Utilizou-se o delineamento estatístico de blocos ao acaso em esquema fatorial $3 \times 6$ (dois fungicidas e a testemunha sem aplicação de fungicida $x$ seis momentos de aplicação) com 4 repetições. Os produtos estão descritos na Tabela 1 e os tratamentos na Tabela 2.

Tabela 1 - Descrição dos produtos utilizados no experimento.

\begin{tabular}{|c|c|c|c|}
\hline \multirow{2}{*}{ Produto } & \multicolumn{2}{|c|}{ Composição } & \multirow{2}{*}{ Formulação } \\
\hline & Ingrediente ativo & Grupo químico & \\
\hline Opera* & piraclostrobina + epoxiconazol & estrubilurina + triazol & suspo/emulsão \\
\hline PrioriXtra* & azoxistrobina + ciproconazol & estrubilurina + triazol & Suspensão concentrada \\
\hline Assist* & óleo mineral & hidrocarboneto parafínicos & Concentrado emulsionável \\
\hline Nimbus* & óleo mineral & hidrocarbonetos alifático & Concentrado emulsionável \\
\hline
\end{tabular}

*O produto comercial utilizado no trabalho não implica em recomendação pelo autor. 
Tabela 2 - Esquema dos tratamentos utilizados no experimento.

\begin{tabular}{|c|c|c|c|}
\hline Tratamento & Momento de aplicação & Produto comercial & Dose $\left(\right.$ L.ha $\left.^{-1}\right)$ \\
\hline 1 & 1 dia após a detecção dos $1^{\circ}$ esporos & Opera + Assist* & 0,5 \\
\hline 2 & 7 dias após a detecção dos $1^{\circ}$ esporos & Opera + Assist* & 0,5 \\
\hline 3 & 14 dias após a detecção dos $1^{\circ}$ esporos & Opera + Assist* & 0,5 \\
\hline 4 & 21 dias após a detecção dos $1^{\circ}$ esporos & Opera + Assist* & 0,5 \\
\hline 5 & $\begin{array}{l}\text { Monitoramento climático } \\
\text { (Sistema Aura - aplicação do produto quando a umidade } \\
\text { relativa for maior que } 0 \% \text { ) }\end{array}$ & Opera + Assist* & 0,5 \\
\hline 6 & $\begin{array}{l}\text { Monitoramento convencional (aplicação do produto após } \\
\text { o início do aparecimento dos } 1^{\text {os }} \text { sintomas - } 1 \% \text { a } 5 \% \text { de } \\
\text { incidência) }\end{array}$ & Opera + Assist* & 0,5 \\
\hline 7 & 1 dia após a detecção dos $1^{\circ}$ esporos & Priori Xtra + Nimbus* & $0,5+0,5 \% \mathrm{v} / \mathrm{v}$ \\
\hline 8 & 7 dias após a detecção dos $1^{\circ}$ esporos & Priori Xtra + Nimbus* & $0,5+0,5 \% \mathrm{v} / \mathrm{v}$ \\
\hline 9 & 14 dias após a detecção dos $1^{\circ}$ esporos & Priori Xtra + Nimbus* & $0,5+0,5 \% \mathrm{v} / \mathrm{v}$ \\
\hline 10 & 21 dias após a detecção dos $1^{\circ}$ esporos & Priori Xtra + Nimbus* & $0,5+0,5 \% \mathrm{v} / \mathrm{v}$ \\
\hline 11 & $\begin{array}{l}\text { Monitoramento climático } \\
\text { (Sistema Aura - UR > 80\%) } \\
\text { Monitoramento convencional (aplicação do produto após }\end{array}$ & Priori Xtra + Nimbus* & $0,5+0,5 \% \mathrm{v} / \mathrm{v}$ \\
\hline 12 & $\begin{array}{l}\text { o início do aparecimento dos } 1^{\text {os }} \text { sintomas - } 1 \% \text { a } 5 \% \text { de } \\
\text { incidência) }\end{array}$ & Priori Xtra + Nimbus* & $0,5+0,5 \% \mathrm{v} / \mathrm{v}$ \\
\hline 13 & Testemunha (sem controle) & --------- & ------- \\
\hline
\end{tabular}

Cada parcela correspondeu a uma área de 31,5 $\mathrm{m}^{2}$, composta de 7 linhas de $10 \mathrm{~m}$ de comprimento, com espaçamento de 0,45 m entre linhas e média de 18 sementes por metro linear, sendo utilizada a cultivar de soja CD 214RR. Foi efetuado tratamento de sementes com os fungicidas sistêmico carboxina e de contato tiran (Vitavax-thiran 200 SC $^{\circledR} 250 \mathrm{~mL}$ p.c./100 kg) e o inseticida sistêmico imidaclopride (Gaucho ${ }^{\circledR} 50 \mathrm{~mL}$ p.c./100 kg) e, em seguida, fez-se a semeadura de forma mecanizada com adubação de base de $300 \mathrm{~kg} /$ ha de 00-20-20, a semeadura foi feita $6 / 11 / 2007$. Como tratos culturais fizeram-se o controle de plantas daninhas com uma aplicação de glifosato e controle de lagartas e percevejos com o inseticida metamidofos (Tamaron $\mathrm{BR}^{\circledR} 500 \mathrm{~mL}$ p.c. $/ 100 \mathrm{~kg})$.

Foram instalados coletores de esporos 'SIGA' (IGARASHI; BALAN, 2004) na área, onde se colocou lâminas de microscopia com uma fita dupla face aderida nelas, para que os esporos presentes na área ficassem aderidos nestas; a cada dois dias, fez-se a coleta das lâminas, juntamente com anotação das condições climáticas obtidas na estação metereológica.

As lâminas coletadas nos coletores foram observadas no microscópio eletrônico, onde se fez a contagem do número de esporos de $P$. pachyrhizi, com base nos aspectos anato-morfologicos, na área da lamínula $(2 \mathrm{~cm} \times 2 \mathrm{~cm})$ que foi colocada em cima da lâmina onde se tinha a fita adesiva com os esporos aderidos, contendo uma gota de água.

Para aplicação dos fungicidas, utilizou-se pulverizador costal pressurizado à base de $\mathrm{CO}_{2}$, com uma largura efetiva de $3 \mathrm{~m}$, e volume de calda de 200 L.ha-1 ${ }^{-1}$ Utilizaram-se para pulverização 6 pontas de jato plano XR110.02. As aplicações foram realizadas de acordo com o descrito na Tabela 3.

Foram avaliadas a área foliar infectada (\%), nível de desfolha (\%) provocado pela ferrugem e produtividade de grãos da soja $\left(\mathrm{kg} \cdot \mathrm{ha}^{-1}\right)$.

Para avaliação da porcentagem de área foliar afetada pela ferrugem, utilizou-se a escala diagramática para avaliação da severidade da ferrugem da soja, proposta por Godoy et al. (2006). Foram feitas avaliações visuais em 6 pontos diferentes ao acaso na parcela, em que se avaliou 10 folhas para cada terço das plantas (baixeira, médio e superior), em 5 plantas, totalizando 30 plantas por parcela, estimando assim a severidade média das plantas inteiras. Essa avaliação foi feita duas vezes por semana até começarem a aparecer os primeiros sintomas, o que ocorreu em $R_{5.1}$ tendo sua evolução efetiva em $R_{5.5^{\prime}}$ procedendo assim até o final do ciclo da cultura. Todavia, para a interpretação dos resultados, foram consideradas as avaliações de ferrugem feitas nos estádios $R_{5.5}$

*O produto comercial utilizado no trabalho não implica em recomendação pelo autor. 
(maioria das vagens entre $75 \%$ e $100 \%$ de granação) e $\mathrm{R}_{8.2}$ (mais de $50 \%$ de desfolha na testemunha sem controle).

A avaliação da desfolha foi feita visualmente considerando a porcentagem da desfolha na planta. Esta avaliação ocorreu no estádio $R_{8.2^{\prime}}$ ocasião em que a testemunha sem controle atingiu mais de 95\% de desfolha.

A produtividade de grãos foi obtida após a colheita realizada no dia 22 de março, ceifando-se manualmente uma área útil de $10 \mathrm{~m}^{2} /$ parcela e trilhando as plantas mecanicamente. Após a pesagem das sementes das parcelas, os resultados de produtividade de grãos foram corrigidos a umidade de $13 \%$ e transformados em quilogramas por hectare.

Os dados obtidos foram submetidos à análise, sendo as médias comparadas pelo teste de Tukey a $5 \%$ de probabilidade.

\section{RESULTADOS E DISCUSSÃO}

Os primeiros esporos foram constatados no dia $30 / 1 / 2008$, e a $1^{\text {a }}$ aplicação feita no dia $31 / 1 / 2008$ (1 dia após o surgimento dos primeiros esporos), e as demais aplicações, conforme demonstrado na Tabela 3.

As condições climáticas registradas durante o experimento e a detecção dos primeiros esporos da ferrugem estão demonstradas na Figura 1, em que se constatou um período favorável ao desenvolvimento da ferrugem asiática, com aumento da umidade (90\%) e temperatura média $\left(23,5^{\circ} \mathrm{C}\right)$. Condições climáticas semelhantes a essas foram encontradas por CASEY (1979) e ANDrade; ANDrAde (2002), apud Zambolim (2006), que observaram em seus experimentos que temperaturas entre 18 e $26^{\circ} \mathrm{C}$, durante 10 horas de molhamento foliar e 20 e $25^{\circ} \mathrm{C}$, durante 6 horas de molhamento foliar, respectivamente, foram favoráveis ao desenvolvimento da ferrugem.
De acordo com os resultados, pôde-se observar que na primeira avaliação da porcentagem de área foliar afetada pela ferrugem, aos 104 dias após a semeadura (estádio R5.5), quando se comparou os produtos dentro do mesmo momento de aplicação, houve diferença apenas entre os fungicidas quando aplicados aos 21 dias, sendo o fungicida (PrioriXtra + Nimbus)* o que apresentou menor porcentagem de área foliar infectada pelo patógeno (Fig. 2).

Quando se comparou o momento de aplicação dentro do mesmo produto, observou-se que ao se aplicar o (Opera + Assist)* baseado no monitoramento climático, a 1 dia e aos 7 dias após a detecção dos primeiros esporos, estes diferiram dos outros tratamentos apresentando uma menor porcentagem de área foliar infectada. O produto (PrioriXtra + Nimbus)* apresentou menor porcentagem de área infectada quando aplicado seguindo o monitoramento climático, a 1 dia e aos 7 dias após detecção dos primeiros esporos, , diferindo dos outros tratamentos. Contudo, o tratamento realizado aos 7 dias não diferiu estatisticamente da aplicação feita aos 14 dias após a detecção dos primeiros esporos e quando seguiu-se o monitoramento convencional, conforme Figura 2. Na primeira avaliação, a testemunha sem controle (média $=11 \%$ ) diferiu de todos os tratamentos com exceção para a aplicação aos 21 dias após detecção dos primeiros esporos, independente do produto aplicado, pelo teste de Tukey a $5 \%$.

Na segunda avaliação, aos 121 dias após a semeadura (estádio $R_{8.2}$ ), quando se fez a aplicação dos produtos aos 7 dias após a detecção dos primeiros esporos, o fungicida (Opera + Assist)* diferiu do (PrioriXtra + Nimbus) ${ }^{*}$, apresentando menor porcentagem de área foliar infectada. Quando a aplicação foi feita aos 14 e 21 dias após a detecção dos esporos, os produtos também apresentaram diferença estatística entre si, contudo, o fungicida (PrioriXtra + Assist)* foi o que obteve uma menor porcentagem de área foliar infectada (Fig. 3).

Tabela 3 - Cronograma de aplicação dos fungicidas.

\begin{tabular}{|c|c|c|c|c|c|c|}
\hline \multirow{2}{*}{ Tratamentos } & \multicolumn{2}{|c|}{$1^{\mathrm{a}}$ aplicação } & \multicolumn{2}{|c|}{$2^{\mathrm{a}}$ aplicação } & \multicolumn{2}{|c|}{$3^{a}$ aplicação } \\
\hline & prevista & executada & prevista & executada & prevista & executada \\
\hline 1 dia após detecção dos $1^{\circ}$ esporos & $31 / 1 / 08$ & $31 / 1 / 08$ & $18 / 2 / 08$ & $18 / 2 / 08$ & $7 / 3 / 08$ & $7 / 3 / 08$ \\
\hline 7 dias após detecção dos $1^{\circ}$ esporos & $7 / 2 / 08$ & $7 / 2 / 08$ & $25 / 2 / 08$ & $25 / 2 / 08$ & $13 / 3 / 08$ & $13 / 3 / 08$ \\
\hline 14 dias após detecção dos $1^{\circ}$ esporos & $15 / 2 / 08$ & $15 / 2 / 08^{3}$ & $3 / 3 / 08$ & $05 / 3 / 08$ & $21 / 3 / 08$ & $-* *$ \\
\hline 21 dias após detecção dos $1^{\circ}$ esporos & $21 / 2 / 08$ & $21 / 2 / 08$ & $10 / 3 / 08$ & $11 / 3 / 08$ & $28 / 3 / 08$ & $-* *$ \\
\hline Monitoramento Climático (Sistema Aura UR $>80 \%$ ) & $18 / 1 / 08^{1}$ & $18 / 1 / 08$ & $31 / 1 / 08$ & $4 / 2 / 08$ & $18 / 2 / 08$ & $18 / 2 / 08$ \\
\hline Monitoramento Convencional & $4 / 2 / 08^{2}$ & $0 / 2 / 08$ & $24 / 2 / 08$ & $25 / 2 / 08$ & $13 / 3 / 08$ & $-* *$ \\
\hline
\end{tabular}

T'Estádio R2; ${ }^{2}$ detecção dos $1^{\circ}$ sintomas ocorreu no dia $4 / 2 / 08$, devido à chuva, a aplicação foi realizada dia 7/2/08;

${ }^{3}$ Estádio $\mathrm{R}_{5.5 .}{ }^{* *} \mathrm{~A} 3^{\mathrm{a}}$ aplicação não foi realizada devido ao estágio fenológico avançado da planta.

${ }^{*} \mathrm{O}$ produto comercial utilizado no trabalho não implica em recomendação pelo autor. 


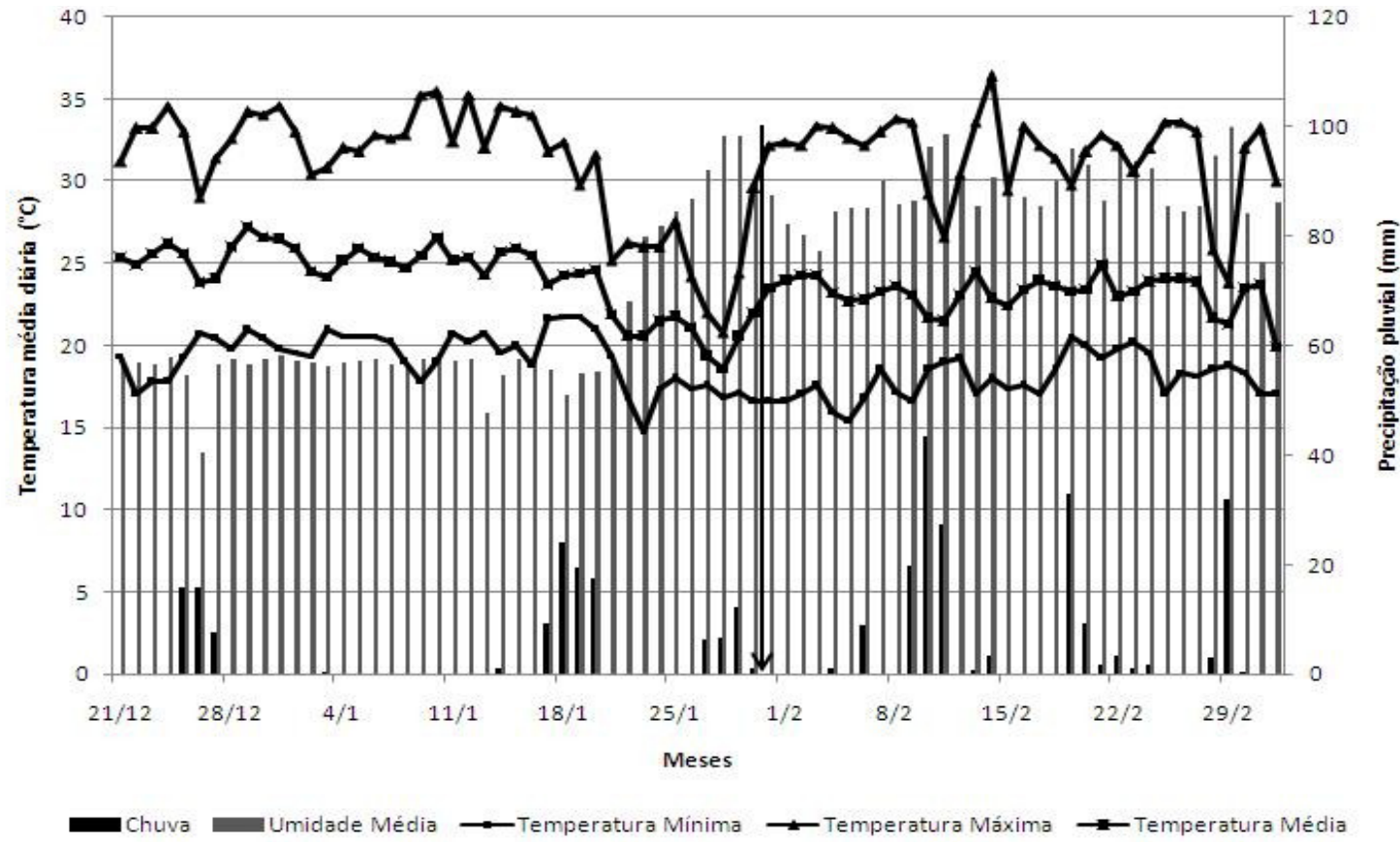

Fig. 1 - Temperatura do ar máxima, média e mínima, precipitação pluviométrica e umidade relativa do ar registradas no período de 21/12/2007 a 3/3/2008 em Londrina, PR, no campus da Universidade Estadual de Londrina.

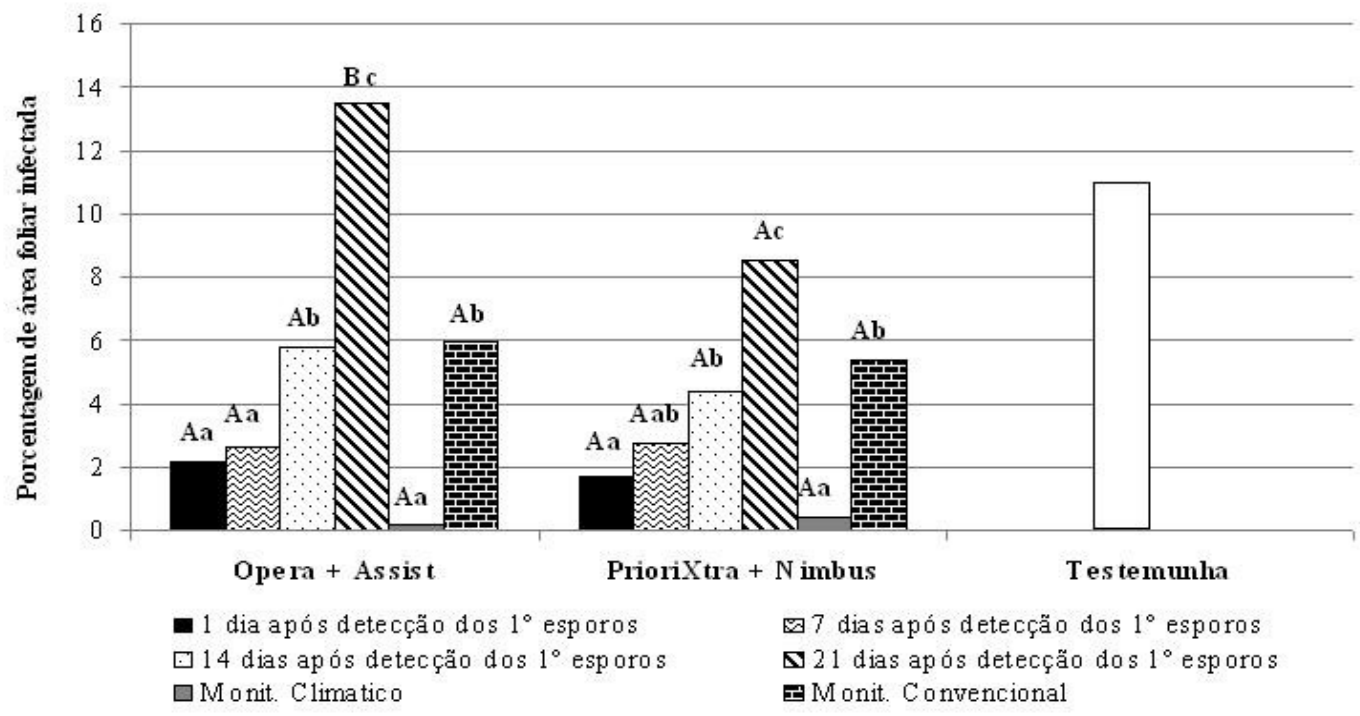

Fig. 2 - Primeira avaliação da porcentagem de área foliar infectada por Phakopsora pachyrhizi, aos 104 dias após a semeadura, correspondente ao estádio $\mathrm{R}_{5.5}$. (Letras maiúsculas, comparação entre os produtos dentro do mesmo momento de aplicação e letras minúsculas, comparação entre os momentos de aplicação dentro do mesmo produto. Letras maiúsculas ou minúsculas iguais não diferem entre si pelo Teste de Tukey a 5\%).

Quando se fez a comparação entre os momentos de aplicação dentro de cada produto, observou-se que o produto (Opera + Assist)* apresentou menor porcentagem de área foliar infectada quando aplicado a 1 dia, aos 7 dias após detecção dos primeiros esporos e seguindo o monitoramento climático, diferindo dos demais tratamentos e (PrioriXtra +
Nimbus)* apresentou menor porcentagem de área foliar infectada, diferindo dos demais tratamentos, quando aplicados a 1 dia após a detecção dos primeiros esporos e seguindo o monitoramento climático (Fig. 3). Na segunda avaliação, a testemunha sem controle (média $=97,5 \%$ ) diferiu de todos os tratamentos pelo teste de Tukey a $5 \%$.

${ }^{*} \mathrm{O}$ produto comercial utilizado no trabalho não implica em recomendação pelo autor. 


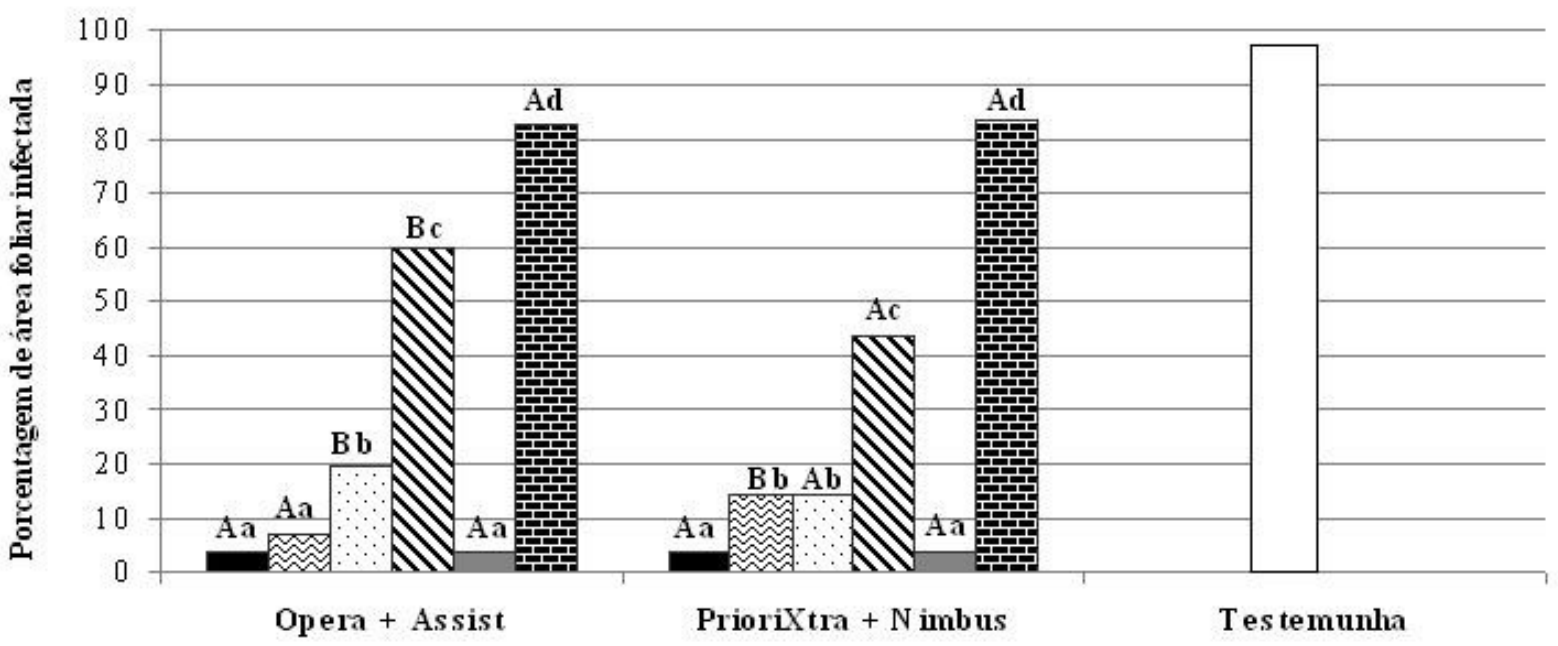

1 dia após detecção dos $1^{\circ}$ esporos

$\square 14$ dias após detecção dos $1^{\circ}$ esporos

$\square \mathrm{M}$ o nit. Climatic 0
Q7 dias após detecção dos $1^{\circ}$ esporos

$\mathbf{\Delta} 21$ dias após detec ção dos $1^{\circ}$ esporos

口 M onit. Convencional

Fig. 3 - Segunda avaliação da porcentagem de área foliar infectada por Phakopsora pachyrhizi, aos 121 dias após a semeadura (estádio $\mathrm{R}_{8.2}$ ). (Letras maiúsculas, comparação entre os produtos dentro do mesmo momento de aplicação e letras minúsculas, comparação entre os momentos de aplicação dentro do mesmo produto. Letras maiúsculas ou minúsculas iguais não diferem entre si pelo Teste de Tukey a 5\%).

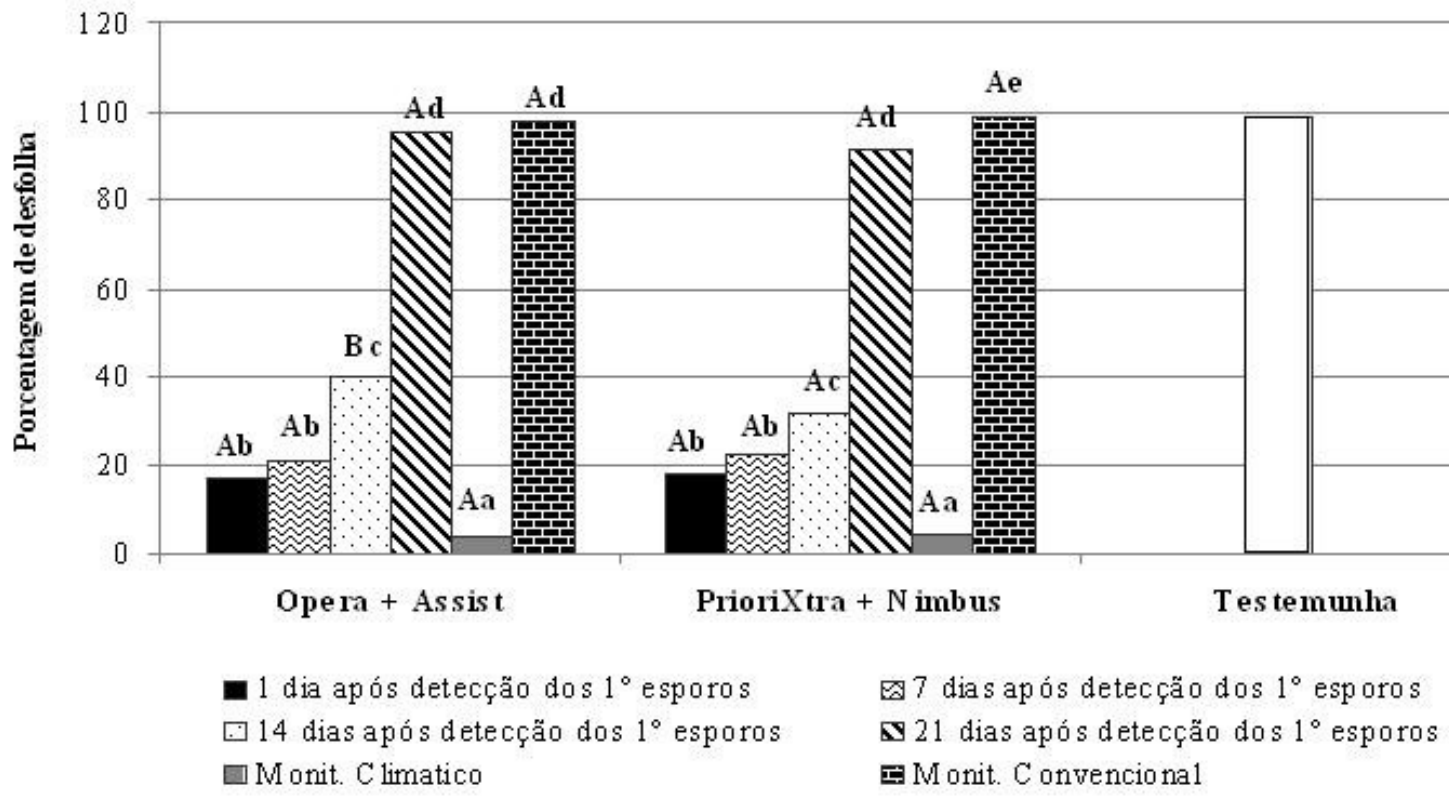

Fig. 4 - Porcentagem de desfolha das plantas de soja infectada por Phakopsora pachyrhizi, aos 121 dias após a semeadura (estádio $\mathrm{R}_{8.2}$ ). (Letras maiúsculas, comparação entre os produtos dentro do mesmo momento de aplicação e letras minúsculas, comparação entre os momentos de aplicação dentro do mesmo produto. Letras maiúsculas ou minúsculas iguais não diferem entre si pelo Teste de Tukey a 5\%).

No geral pôde-se observar que, na primeira avaliação, o monitoramento climático (umidade relativa acima de $80 \%$ ) foi o que apresentou melhor resultado, apresentando uma menor porcentagem de área foliar afetada, independente do produto utilizado, seguido pelas aplicações a 1 dia e 7 dias após a detecção dos esporos.
O mesmo ocorreu na segunda avaliação, em que o monitoramento climático igualou-se a aplicação feita a 1 dia após a detecção dos primeiros esporos, para os dois produtos, em que apresentaram menor porcentagem de área foliar infectada.

Com relação à avaliação da desfolha, quando se fez a comparação entre os produtos dentro do mesmo 
momento de aplicação, verificou-se que o fungicida (PrioriXtra + Nimbus)*, aplicado aos 14 dias após a detecção, diferiu do (Opera + Assist) ${ }^{*}$, apresentando menor porcentagem de desfolha (Fig. 4).

Na comparação dos momentos de aplicação dentro de cada produto, observou-se que, quando se fez a aplicação dos produtos seguindo o monitoramento climático, tanto (Opera + Assist) ${ }^{*}$ e (PrioriXtra + Nimbus)* diferiram dos demais tratamentos, apresentando menor porcentagem de desfolha (Fig. 4). A testemunha sem controle (média $=99 \%$ ) não diferiu dos produtos aplicados seguindo o monitoramento convencional, e também quando se fez a aplicação de (Opera + Assist)* aos 21 dias após a detecção dos primeiros esporos, pelo teste de Tukey a $5 \%$.

Quanto à produtividade de grãos da cultura, avaliando-se os produtos dentro da mesma época de aplicação, observou-se que não houve diferença estatística entre os fungicidas (Opera + Assist)* e (PrioriXtra + Nimbus) $^{*}$ aplicados nos diferentes momentos de aplicação (Fig. 5).

E quando se comparou cada produto dentro dos diferentes momentos de aplicação observou-se que não houve diferença estatística entre os tratamentos para o fungicida (Opera + Assist)*. No entanto, pôde-se observar que para o produto (PrioriXtra + Nimbus)* houve diferença estatística entre os tratamentos quando se aplicou o produto a 1dia e 21 dias após a detecção dos primeiros esporos, e quando seguiu o monitoramento convencional (Fig. 5). A testemunha sem controle $\left(\right.$ média $\left.=2.579,1 \mathrm{~kg} \cdot \mathrm{ha}^{-1}\right)$ diferiu apenas do tratamento em que se aplicou (PrioriXtra + Nimbus)* a 1 dia após a detecção dos primeiros esporos, pelo teste de Tukey a $5 \%$.

Nogeral, pôde-se observarque o melhor momento para aplicação do produto foi utilizando o monitoramento climático, pois, independente do produto foi o queapresentou uma menor porcentagem de desfolha, comparado com os demais (Fig. 4). Em relação à produtividade da cultura, o produto (Opera + Assist) ${ }^{*}$ aplicado nos diferentes momentos não interferiu nele, e quando se fez a aplicação do produto (PrioriXtra + Nimbus)* , a 1 dia após a detecção dos primeiros esporos e seguindo o monitoramento climático, obteve-se maior produtividade de grãos (Fig. 5).

Trabalhos deste gênero relacionados à ferrugem asiática da soja são raros ou mesmo inexistentes na literatura, por isso a dificuldade de se comparar com os resultados obtidos neste experimento. No entanto, há trabalhos realizados com outras culturas e doenças, em que os autores obtiveram melhor controle e eficiência dos produtos aplicados, e em alguns casos foi possível até diminuir o número de aplicações como, por exemplo, quando utilizaram sistema de previsão para a requeima da batata (COSTA et al., 2002) e requeima do tomateiro (DuARTE et al., 2007), baseando-se no valor da severidade da doença e também o método de monitoramento para o controle da mancha preta e verrugose do amendoim (MoraEset al., 2001), em que se basearamnaincidência de manchas foliares, associando com as condições climáticas favoráveis ao desenvolvimento da doença.

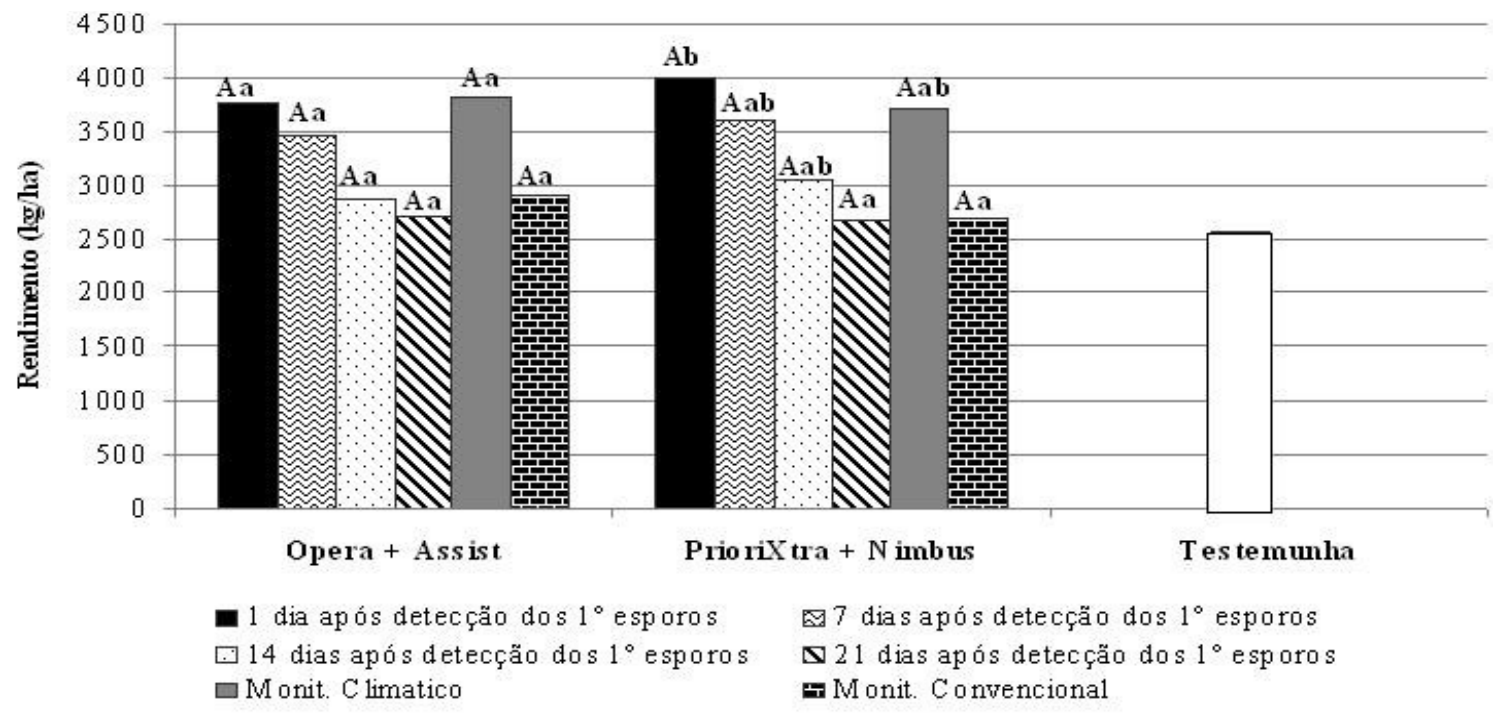

Fig. 5 - Produtividade de grãos (kg.ha-1) das plantas de soja infectada por Phakopsora pachyrhizi. (Letras maiúsculas, comparação entre os produtos dentro do mesmo momento de aplicação e letras minúsculas, comparação entre os momentos de aplicação dentro do mesmo produto. Letras maiúsculas ou minúsculas iguais não diferem entre si pelo Teste de Tukey a $5 \%$ ).

*O produto comercial utilizado no trabalho não implica em recomendação pelo autor. 
Estudos sobre a utilização de métodos de monitoramento para indicar o melhor momento para o início das aplicações de fungicida fazem-se necessários para o sucessodocontroledaferrugem, pois, segundoZAMBOLIM (2006), a prática demonitoramento deinóculo presentes no ar, por meio de armadilhas do tipo caça esporos, também pode constituir-se uma ferramenta valiosa na decisão do controle químico da doença. Independentemente da fonte de origem, a presença de esporos no ar indica que, se as condições climáticas forem favoráveis, muito provavelmente haverá infecção da soja nos dias subsequentes, caso as variedades sejam suscetíveis.

Nocaso específico da realização desse trabalho, em que a evolução da ferrugem asiática as soja ocorreu tardiamente no ensaio, iniciando-se o contraste de severidade a partir de R5.4-5 chegando a testemunha sem controle a $97 \%$ de severidade já nos estádios de maturação fisiológica (R8), os resultados mostraram conclusões bastante pertinentes no tocante ao manejo químico da ferrugem asiática e principalmente ao timing da primeira aplicação de fungicida na cultura visando o controle dessa doença. Entretanto, há necessidade de mais estudos embasados nesses resultados, explorando diferentes condições de pressão de doença, bem como cultivares com diferentes níveis de tolerância e em condições climáticas diversas para confirmação e consolidação dessa nova tecnologia.

\section{CONCLUSÃO}

Nascondiçõesderealizaçãodopresenteexperimento ecombasenos resultadosobtidos, pode-seconcluirque: - os produtos (Opera + Assist)* e (PrioriXtra + Nimbus)* aplicados logo no início da detecção dos primeiros esporos, seguindo o monitoramento climático, proporcionam menor porcentagem de infecção da ferrugem asiática da soja.

\section{AGRADECIMENTOS}

À CAPES - Coordenação de Aperfeiçoamento de Pessoal de Nível Superior, pelo apoio financeiro.

\section{REFERÊNCIAS}

ANDRADE, P.J.M.; ANDRADE, D.F.A. Ferrugem asiática: uma ameaça a sojicultura brasileira. Dourados: Embrapa, 2002. 11p. (Circular técnica, n.11.).

BALARDIM, R. S. Situação, importância e perspectivas de evolução da ferrugem asiática nos principais países produ- tores. In: CONGRESSO BRASILEIRO DE SOJA, 4., 2006, Londrina, PR. Anais. Londrina: Embrapa Soja, 2006. p.94-96.

CASEY, P. S. The epidemiology of soybean rust - Phakospsora pachyrhizi Sydow. Sydney, 1979. Tese (Doutorado) - University of Sydney, Sydney, 1979.

COSTA, R.V.; ZAMBOLIM, L.; VALE, F.X.R. do; MIZOBUTI, E.S.G. Previsão da requeima da batateira. Fitopatologia brasileira, v.27, n.4, p.349-354, 2002.

DUARTE, R. N. Eficácia de fungicidas no controle da ferrugem da soja. 2004. $32 \mathrm{f}$. Monografia (pesquisa em Agronomia) - Universidade de Rio Verde, Rio Verde, GO, 2004.

DUARTE, H. da S.S.; ZAMBOLIM, L.; JESUS JUNIOR, W.C. de Manejo da requeima do tomateiro industrial empregando sistema de previsão. Summa Phytopathologica, v.31, n.4, p.328-334, 2007.

GODOY, C.V; KOGA, L.; CANTERI, M.G. Diagrammatic Scale for Assessment of Soybean Rust Severity. Fitopatologia Brasileira, v.31, n.1, p.63-68, 2006.

IGARASHI, S.; BALAN, M.G. Ferrugem na Sojasoja. Direto do Vale, Vale do Paranap6 ago. 2004. v.1, 1-8p.

MORES, S. A.; GOOY, I. J.; PEZZOPNE J. R. M.; PERERA J C V. N. A.; SILVERA, L. C.P. Eficiência de fungicidas no controle da mancha preta e verrugose do amendoim por método de monitoramento. Fitopatologia Brasileira, v.26, n.2, p.134-140, 2001.

REIS, E. M. (Ed.). Previsão de doenças de plantas. Passo fundo, RS: Universidade de Passo Fundo, 2004.

SIVA L H. C. P. Controle químico da ferrugem da soja. São Paulo: Conselho Syngenta de Fitopatologia, 2003.

YORINORI, J. T. Situação atual das doenças potenciais no cone sul. In: CONGRESSO BRASILEIRO DE SOJA, 2., 2002, Foz do Iguaçú, PR. Anais. Londrina: Embrapa Soja, 2002. p.171- 187.

YORINORI, J. T. Ferrugem "asiática" da soja: o desafio continua e como aprimorar o seu controle. In: $\mathrm{CON}$ GRESSO BRASILEIRO DEOJA, IV4., 2006, Londrina, PR. Anais. Londrina: Embrapa Soja, 2006. p.101-187.

ZAMBOLIM, L. Manejo integrado da ferrugem asiática da soja. In.: (Ed.). Ferrugem asiática da soja. Viçosa: Universidade Federal de Viçosa, 2006. p.73-98.

Recebido em 12/1/08

Aceito em 16/6/10

*O produto comercial utilizado no trabalho não implica em recomendação pelo autor. 